\title{
Approches de l'araire en Himalaya
}

Pascale Dollfus, Marie Lecomte-Tilouine et Denis Blamont

\section{OpenEdition}

Journals

Édition électronique

URL : https://journals.openedition.org/tc/252

DOI : $10.4000 /$ tc. 252

ISSN : 1952-420X

Éditeur

Éditions de l'EHESS

\section{Édition imprimée}

Date de publication : 1 juillet 2001

Pagination : 1-2

ISSN : 0248-6016

\section{Référence électronique}

Pascale Dollfus, Marie Lecomte-Tilouine et Denis Blamont, « Approches de l'araire en Himalaya », Techniques \& Culture [En ligne], 37 | 2001, mis en ligne le 20 octobre 2005, consulté le 29 septembre 2022. URL : http://journals.openedition.org/tc/252 ; DOI : https://doi.org/10.4000/tc.252

Ce document a été généré automatiquement le 29 septembre 2022.

Tous droits réservés 


\title{
Approches de l'araire en Himalaya
}

\author{
Pascale Dollfus, Marie Lecomte-Tilouine et Denis Blamont
}

1 L'étude d'un outil comme l'araire est moins simple qu'il n'y paraît, surtout lorsqu'il s'agit d'en comprendre la variété à grande échelle. En effet, si dans un village ou une vallée, les diverses conceptions indigènes expliquant la préférence pour un modèle particulier peuvent être cohérentes, en revanche, dans une région peuplée par des groupes différents, non seulement aucun discours ne saurait à lui seul rendre compte de l'ensemble des phénomènes, mais encore, nulle logique technique n'est généralisable. D'une certaine façon, les chercheurs n'échappent pas à cette loi. Autant leurs prises de position semblent peu importer quand ils décrivent un outil en un lieu donné, autant elles peuvent paraitre contradictoires dans un vaste espace de comparaison.

Des quatre contributions ici réunies, deux traitent d'un seul type d'araire et en examinent tous les aspects: structure, nomenclature, fabrication, fonctions et techniques d'utilisation; ce sont celles de V. Labbal pour le Ladakh, et de D. Baudais et K. Lundström-Baudais pour la région de Jumla au Népal occidental. Les deux autres articles tentent d'appréhender l'outil, à partir non pas de l'un de ses types, mais d'une région: l'Himalaya. P. Dollfus, M. Lecomte-Tilouine et $\mathrm{O}$. Aubriot, partant d'une classification morphologique, dressent une carte de la répartition des types d'araires en Himalaya, puis la comparent à une carte linguistique qui porte sur la nomenclature locale de l'instrument. Ces auteurs tentent d'expliquer de telles configurations par l'histoire des populations : migrations et dominations. En retour, elles leur ont permis de contester les hypothèses communément admises sur le peuplement du Népal.

3 Tout autre est l'approche de D. Blamont. Sans nier le rôle déterminant des influences «culturelles » régionales, celui-ci propose une taxinomie des araires fondée non sur leurs formes, mais sur leur adaptation aux contraintes (climat, nature du sol, degré de pente, rareté du bois, savoir faire et coûts de fabrication). Il dégage ainsi trois grandes «tendances » qui correspondent chacune à une région géographique du Népal : araire des hautes terres arides du nord, araire des champs enterrasses ou en pente des moyennes montagnes, plus humides, araire, enfin, de la plaine du Teraï aux sols fins et 
lourds. L'auteur insiste plus particulièrement sur la forme du soc, pièce jusqu'à présent négligée dans les études morphologiques de cet outil.

4 Au-delà d'un modèle idéal indexé sur une région et transmis de génération en génération, des traits communs regroupent des araires de types différents mais utilisés dans un étage géographique identique que caractérisent de mêmes données phytologiques, pédologiques et climatiques.

5 Ces différentes approches, loin de s'exclure, montrent une fois de plus qu'on ne peut rendre compte d'un fait technique que par des faisceaux de déterminants dont la hiérarchie varie d'un acteur à l'autre, d'une région, ou d'une culture à l'autre. 